Received Date : 29-Jul-2016

Revised Date : 14-Oct-2016

Accepted Date : 18-Nov-2016

Article type : Original Article-Basic Mechanisms in Allergic Disease

\title{
Title: Neutrophil activation during acute human anaphylaxis: analysis of MPO and
} SCD62L

Short title: Neutrophil activation during human anaphylaxis

Abbie Francis $^{1,2}$, Erika Bosio ${ }^{1,2}$, Shelley F Stone ${ }^{1,2}$, Daniel M Fatovich ${ }^{1,2,3}$, Glenn Arendts ${ }^{1,2,3,4}$, Yusuf Nagree $^{1,4,5}$, Stephen PJ Macdonald ${ }^{1,2,3,6}$, Hugh Mitenko ${ }^{1,7}$, Mani Rajee $^{1,8}$, Sally Burrows ${ }^{9}$, and Simon GA Brown ${ }^{1,2,3,10}$

1. Centre for Clinical Research in Emergency Medicine, Harry Perkins Institute of Medical Research, Perth, Australia

2. Discipline of Emergency Medicine, School of Primary, Aboriginal and Rural Health Care, University of Western Australia, Perth, Australia

3. Emergency Department, Royal Perth Hospital, Perth, Australia

4. Fiona Stanley Hospital, Murdoch, Australia

5. Emergency Department, Fremantle Hospital, Fremantle, Australia

6. Emergency Department, Armadale Kelmscott Memorial Hospital, Mount Nasura, Australia

7. Emergency Department, South West Health Campus, Bunbury, Australia

8. Emergency Department, Austin Hospital, Heidelberg, Australia

9. School of Medicine \& Pharmacology, University of Western Australia, Perth, Australia

10. Emergency Department, Royal Hobart Hospital, Hobart, Australia

This article has been accepted for publication and undergone full peer review but has not been through the copyediting, typesetting, pagination and proofreading process, which may lead to differences between this version and the Version of Record. Please cite this article as doi: 10.1111/cea. 12868

This article is protected by copyright. All rights reserved. 
Corresponding Author: Abbie Francis, Centre for Clinical Research in Emergency Medicine, Harry Perkins Institute of Medical Research, Level 6 MRF Building, Rear 50 Murray Street, Perth, Western Australia 6000.

Phone: +61 892240356 Email: Abbie.Francis@uwa.edu.au

\begin{abstract}
Background

The mechanisms involved in the amplification of the mast cell response during anaphylaxis are unclear. Mouse models of anaphylaxis demonstrate the critical involvement of neutrophils. These innate immune cells are highly abundant in peripheral blood and can be rapidly activated to trigger both local and systemic inflammation.
\end{abstract}

\title{
Objective
}

To investigate neutrophil activation in peripheral blood during acute human anaphylaxis.

\section{Methods}

Patients presenting to the Emergency Department with anaphylaxis underwent blood sampling upon enrolment and at up to three subsequent time points. Traditional anaphylaxis biomarkers, histamine and mast cell tryptase, were measured by ELISA and ImmunoCAP respectively. Plasma myeloperoxidase concentrations were measured by ELISA, serum soluble CD62L concentrations by cytometric bead array, and both compared to healthy controls.

Results

In 72 patients, $37(51 \%)$ had severe anaphylaxis, 33 (60\%) were histamine positive, and $47(70 \%)$ were mast cell tryptase positive. At enrolment, myeloperoxidase concentrations were 2.9- (95\% CI: $1.3,6.5)$ and 5.0- (95\% CI: 2.4, 10.5) fold higher in moderate and severe patients respectively, compared with healthy controls, and remained stable over the first 5 hours following symptom onset. At enrolment, soluble CD62L was $29 \%$ (95\% CI: 19, 38) and 31\% (95\% CI: 22, 40) lower in moderate and severe patients respectively, than healthy controls, and was stable over the first 5 hours. There were no associations between myeloperoxidase or soluble CD62L concentrations and either histamine or mast cell tryptase concentrations.

\section{Conclusions and Clinical Relevance}

These results provide compelling evidence for the involvement of neutrophils during acute human anaphylaxis, suggesting they are activated early in the reaction, regardless of mast cell activation. This important finding increases our understanding of the basic mechanisms of anaphylaxis, a necessary precursor to improving treatment and prevention.

This article is protected by copyright. All rights reserved. 


\title{
Key words:
}

Anaphylaxis; basic mechanisms; clinical immunology; granulocyte; neutrophil; peripheral blood leukocyte

\author{
Abbreviations \\ AH - Austin Hospital \\ AKMH - Armadale Kelmscott Memorial Hospital \\ $\mathrm{CI}$ - confidence interval \\ CISS - Critical Illness and Shock Study \\ ED - Emergency Department \\ FH - Fremantle Hospital \\ $\mathrm{IQR}$ - interquartile range \\ MCT - mast cell tryptase \\ MLE - Maximum Likelihood Estimation \\ MPO - myeloperoxidase
}

NIAID/FAAN - National Institute of Allergy and Infectious Diseases/Food Allergy and Anaphylaxis Network

RPH - Royal Perth Hospital

sCD62L - soluble L-selectin

SWHC - South West Health Campus

TREM-1 - triggering receptor expressed on myeloid cells-1

\section{Introduction}

Allergies are a growing health concern with an increase in the number of children experiencing adverse food reactions, and adults having reactions to drugs, reported over the last 20 years $[1,2]$. Anaphylaxis is a serious and potentially life-threatening allergic reaction that affects multiple organ systems, characterized by hives/rash, bronchospasm, and collapse [3]. Mild reactions involve only the skin and subcutaneous tissue, moderate reactions involve additional organ systems, and the presence of hypotension, hypoxia, or neurological compromise at any point indicates a severe reaction [4].

This article is protected by copyright. All rights reserved. 
In humans, IgE-mediated anaphylaxis requires sensitization whereby the initial exposure to an allergen stimulates the production of allergen-specific IgE, which bind to $\operatorname{IgE}$ receptors on the surface of effector cells, such as mast cells. On subsequent exposure, the allergen binds to these IgE resulting in cross-linkage which activates tissue mast cell populations. This results in the local release of an array of pro- and anti-inflammatory mediators, cytokines and chemokines. This response is measured systemically by increases in traditional markers of anaphylaxis, histamine and mast cell tryptase (MCT), which are widely reported to correlate with reaction severity [5-11]. The half-life of MCT in the bloodstream is approximately 2 hours [12], considerably longer than that of histamine which reportedly returns to baseline within 60 minutes of reaction onset [7, 12]. Therefore, MCT is the preferred clinical biomarker for anaphylaxis.

The processes that rapidly amplify the initial antigenic stimulation of mast cells into a potentially life-threatening systemic reaction remain unclear, although research by our group and others suggest that neutrophils may play an important role. Neutrophils have been shown to be important in mouse models of anaphylaxis wherein depletion of neutrophils completely inhibited anaphylaxis, whilst replenishment with either mouse or human neutrophils restored anaphylactic potential [13]. In addition, a microarray investigation of human anaphylaxis performed in our laboratory identified the upregulation of major inflammatory pathways including the toll-like receptor and triggering receptor expressed on myeloid cells-1 (TREM-1) pathways, which suggested early involvement of the innate immune system and neutrophil activation [14]. Upon activation, neutrophils release neutrophil elastase, collagenase, and gelatinase which have been implicated in the degradation of the extracellular matrix [15, 16], as well as lactoferrin, which up-regulates neutrophil adhesion molecules and delays apoptosis $[17,18]$. Activated neutrophils also produce and/or release cytokines such as IL-1, IL-6, IL-8, IL-12, tumor necrosis factor $\alpha$, and transforming growth factor $\beta$, which may amplify anaphylaxis by activating additional neutrophils and other immune cells [19]. Therefore, it is likely that neutrophil activation may be one mechanism driving the rapid systemic activation of the immune system as seen in anaphylaxis. To date, no studies have examined neutrophil activation in human patients experiencing active symptoms of acute anaphylaxis.

Neutrophil activation is most commonly assessed by the measurement of activation markers in serum and plasma such as myeloperoxidase (MPO) [20], soluble L-selectin (sCD62L) [21], elastase [22], IL-8 [22, 23], and S100A12 [24, 25]. MPO is an enzyme confined within neutrophil azurophilic granules and released upon their activation [20]. Elevated MPO levels in peripheral blood have been widely reported as a marker of neutrophil activation and degranulation, and the concentration of MPO provides a measure of the degree of activation [20, 26, 27]. CD62L is an adhesion molecule present on the surface of most leukocytes including neutrophils, and is involved in the initial attachment to endothelial walls at the site of inflammation [19,28]. Upon activation, CD62L proteins are enzymatically cleaved from the neutrophil surface, releasing SCD62L into the circulation [21, 29]. This shedding enables the translocation of the $\beta_{2}$ integrin $\mathrm{CD} 11 \mathrm{~b}$ to the cell surface, required for tight binding to the endothelium [30]. sCD62L levels are elevated in some inflammatory disease states and reduced in others, despite showing similar evidence for immune cell activation. Elevated sCD62L concentrations have been observed in systemic lupus erythematosus [31], acute myeloblastic leukaemia and insulin-dependent diabetes mellitus [32], whilst reduced SCD62L has been associated with poor outcomes in trauma [33-35] and acute lymphoblastic leukaemia [36]. This suggests the sCD62L shedding/binding process is influenced by a number of factors and may be disease specific. Since neither MPO nor sCD62L have been investigated in patients with anaphylaxis or allergy,

This article is protected by copyright. All rights reserved. 
particularly during an active reaction, this study aimed to measure concentrations of these markers during anaphylaxis; to identify variations from healthy control levels; and investigate associations with reaction severity.

\section{Materials and Methods}

\section{Patient recruitment}

Study participants and healthy controls were enrolled in our prospective, observational Critical Illness and Shock Study (CISS) between September 2010 and April 2015 in the Emergency Departments (ED)s of five Australian hospitals: Royal Perth Hospital (RPH), Perth WA; Fremantle Hospital (FH), Fremantle WA; Armadale Kelmscott Memorial Hospital (AKMH), Mount Nasura WA; South West Health Campus (SWHC), Bunbury WA; and Austin Hospital (AH), Heidelberg VIC. The CISS methodology has been previously described [37]. Briefly, patients enrolled in CISS meet a case definition of critical illness, and then undergo serial blood sampling and clinical data collection at protocolled time points. CISS enrolment criteria exclude mild (skin-only) allergic reactions.

Ethics approval and consent

Ethics approval was obtained from the Human Research Ethics Committees at each hospital (RPH, FH, AKMH: EC 2009/080; SWHC: 2012:31; AH: H2012/04477). As the need for emergency care took priority, waiver of initial consent was approved under the provision of paragraph 2.3.6 of the National Health and Medical Research Council Ethical Conduct guidelines (2007). Once treatment was started, fully informed written consent was obtained as soon as possible and patients were given the option of declining further involvement and having all research samples collected up to that point destroyed.

\section{Case selection}

We selected cases that; (i) satisfied a clinical definition of anaphylaxis based on National Institute of Allergy and Infectious Diseases/Food Allergy and Anaphylaxis Network (NIAID/FAAN) criteria [3], and (ii) had blood sampling initiated within 180 minutes of symptom onset. Healthy controls for this study were selected to match the age and sex distributions of the patient cohort.

\section{Case classification}

In order to investigate changes associated with disease severity, cases were reviewed by two clinical investigators (SB and GA) and classified into two severity groups, moderate and severe anaphylaxis, based on clinical features according to standard consensus criteria [4]. Severe anaphylaxis was defined as the presence of hypoxia (cyanosis or $\mathrm{SpO}_{2} \leq 92 \%$ ), hypotension (systolic blood pressure $<90 \mathrm{mmHg}$ ), and/or neurological compromise (confusion, collapse, or loss of consciousness) at any stage. Moderate anaphylaxis was defined as meeting the definition of anaphylaxis and involving multiple organ systems, in the absence of hypoxia, hypotension, or neurological compromise. This clinical classification was undertaken separately and blinded to the laboratory analyses.

This article is protected by copyright. All rights reserved. 


\section{Blood sampling and storage}

Blood samples were collected as soon as practicable after enrolment criteria were met in the ED (T0), between 1-2 (T1), and 3-6 (T3) hours post enrolment, and finally within 3 hours of discharge. At each time point, 2 x $4 \mathrm{~mL}$ EDTA plasma tubes and $1 \times 3.5 \mathrm{~mL}$ serum tube were collected, processed and aliquots of plasma and serum stored immediately at $-80^{\circ} \mathrm{C}$ until analysis.

\section{Histamine measurement}

Histamine concentrations were measured in neat patient plasma in duplicate using validated, pre-coated histamine ELISA according to the manufacturer's standard protocol (IBL International, Germany). The lower limit of detection of plasma histamine was $0.014 \mathrm{ng} / \mathrm{mL}$. A positive result was defined as a peak plasma histamine concentration greater than $1.2 \mathrm{ng} / \mathrm{mL}$, the $99^{\text {th }}$ percentile of healthy control samples measured using this technique in our laboratory during a previous study [6]. The pre-coated and validated histamine ELISA plates met the quality standards set by the manufacturer, and intra assay CVs were $4.6 \%$.

\section{Mast cell tryptase measurement}

The concentration of MCT in neat patient sera was measured using the ImmunoCAP ${ }^{\circledR}$ system according to the manufacturer's recommended protocol. Concentrations higher than $11.4 \mathrm{ng} / \mathrm{mL}$ were considered positive, as defined by the $95^{\text {th }}$ percentile of healthy controls determined by the manufacturer (Phadia, Sweden). In addition, as determined by our previous study, an MCT result was also considered positive where a difference (i.e. delta-MCT) of $2.0 \mathrm{ng} / \mathrm{mL}$ or more was evident between the minimum and maximum values for each patient [5]. The lower limit of detection for serum MCT was $0.707 \mathrm{ng} / \mathrm{mL}$.

\section{Myeloperoxidase measurement}

Plasma MPO concentrations were measured in duplicate using ELISA according to the manufacturer's standard protocol (Duoset R\&D Systems, USA). Samples were diluted 1:100, 1:150, or 1:200, as required, in Reagent Diluent (1\% BSA/PBS, $\mathrm{pH} 7.2-7.4,0.2 \mu \mathrm{M}$ filtered) prior to analysis. The lower limit of detection for plasma MPO was $0.0442 \mathrm{ng} / \mathrm{mL}$. Intra and inter assay CVs for MPO ELISAs were $3.4 \%$ and $14.3 \%$, respectively; recovery was $107 \%$ and linearity was $112 \%$.

\section{Soluble CD62L measurement}

Serum concentrations of $\mathrm{sCD} 62 \mathrm{~L}$ were measured using a cytometric bead array flex set (BD Biosciences, USA) as previously described [6]. Prior to analysis for sCD62L, serum samples were diluted 1:40 and 1:80, or 1:100 and 1:200, as necessary. The final result for each sample was calculated as the mean concentration after correction for the appropriate dilution factors. Samples were measured using a BD FACSCanto II (BD Biosciences, USA) and analysed using FCAP Array v3.0 software (Soft Flow, Hungary). The lower limit of detection for serum sCD62L was 0.020 $\mathrm{ng} / \mathrm{mL}$.

This article is protected by copyright. All rights reserved. 


\section{Statistical analysis}

Patient demographics and clinical data are presented as mean (SD) or count (\%) for continuous or class variables, respectively. Pearson's $\chi^{2}$ tests were used to analyse differences in proportions and two-sample $t$ tests were used to examine differences in means for age and time since symptom onset between severity groups. Mediator concentrations were log transformed to normalize the distribution of results. Linearity of continuous covariates was examined using multivariate regression splines and fractional polynomials. Random effects linear regressions with Maximum Likelihood Estimation (MLE) were employed to analyse continuous outcomes measured over time. MLE is a technique that retains those with incomplete data thus avoiding complete case bias and is known to produce unbiased estimates when data are missing at random. It uses a combination of complete and incomplete data to produce the most likely estimate for the whole sample. Due to undetectable concentrations in some samples, random effects Tobit regression models were used for histamine, MCT, and MPO to account for the censored data. Models initially included the interaction of group and time (in categories) to test for unadjusted differences between groups at each time point. To investigate patterns over time within and between groups, the time categories were replaced with minutes since symptom onset. Models were then adjusted for age, sex, and reaction trigger. Results are presented as the fold change (the ratio of two geometric means) and the corresponding 95\% confidence interval (CI). Associations between mediators were also investigated using random effects linear regression and random effects Tobit regression models as appropriate, adjusted for age, sex, and reaction trigger. P-values $<0.05$ were deemed significant, no adjustments were made to the significance level to account for multiple comparisons due to the exploratory nature of this study. Statistical analysis was performed with Stata v.12.1 (StataCorp, USA).

\section{Results}

\section{Cohort characteristics}

This study cohort comprised 72 patients that met the clinical definition of anaphylaxis, 37 $(51 \%)$ of these were classified as severe reactions. The patient demographics and clinical characteristics are described in Table 1 . Patients with moderate anaphylaxis were younger $(\mathrm{p}=0.007)$. Moderate reactions were primarily triggered by food sensitivities whilst the majority of severe cases were adverse reactions to drugs. Eight (11\%) reactions were triggered by insect venom and only four $(6 \%)$ were summative anaphylaxis with physical triggers (food + exercise). The median time from onset of symptoms to study enrolment was 73.5 minutes (interquartile range (IQR): 45.5), ranging from 10 minutes to 155 minutes, and was similar for both groups $(\mathrm{p}=0.480)$. A higher proportion of severe patients received pre-hospital adrenaline and fluid therapy $(\mathrm{p}=0.007$ and $\mathrm{p}=0.009$, respectively).

\section{Histamine and mast cell tryptase are elevated in anaphylaxis patients}

Plasma histamine concentrations were positive at any time point in $33(60 \%)$ of all anaphylaxis patients (52\% of moderate patients and $66 \%$ of severe patients) (Table 1 ). A summary of the raw histamine concentrations with unadjusted comparisons at each timepoint between reaction severity groups is shown in Figure 1A. At the time of enrolment in the study, histamine 
concentrations were 5.8- (95\% CI: 1.2, 27.1) fold higher in severe patients compared to those with moderate reactions $(\mathrm{p}=0.025)$. Histamine levels decreased by $20 \%$ (95\% CI: 10,28$)$ every hour since the onset of symptoms $(\mathrm{p}<0.001)$, with no difference in trend between the two reaction severities $(\mathrm{p}=0.618)$ (Figure 2A).

Serum MCT concentrations were positive in 47 (70\%) of anaphylaxis patients and significantly more severe reactions had elevated MCT than moderate reactions with 32 (89\%) and 15 (48\%), respectively $(\mathrm{p}<0.001)$ (Table 1$)$. A summary of the raw MCT concentrations with unadjusted comparisons at each timepoint according to reaction severity is shown in Figure 1B. At enrolment, concentrations of MCT were 2.6- (95\% CI: 1.6, 4.1) fold higher in severe patients than in moderate patients ( $\mathrm{p}<0.001)$. MCT concentrations decreased by $5.5 \%$ (95\% CI: $4.5,6.4)$ per hour since symptom onset $(\mathrm{p}<0.001)$, with no difference in trend between the two severities $(\mathrm{p}=0.811)$ (Figure 2B).

\section{Myeloperoxidase was consistently elevated during anaphylaxis}

The raw MPO concentrations at each timepoint are summarised according to reaction severity in Figure 1C, with unadjusted comparisons between severities as indicated. In healthy controls $(\mathrm{n}=23)$, the median (IQR) MPO concentration was 16.24 (12.08) ng/mL. At enrolment, MPO concentrations were 2.9 (95\% CI: 1.3, 6.5) fold higher in moderate patients compared with healthy controls ( $\mathrm{p}=0.008)$, and 5.0 (95\% CI: 2.4, 10.5) fold higher in severe patients than healthy controls $(\mathrm{p}<0.001)$. At enrolment, MPO concentrations were not significantly different between moderate and severe patients, or between patients who received adrenaline pre-hospital and those who did not ( $\mathrm{p}=$ 0.143 and $\mathrm{p}=0.248$, respectively). There were no significant changes in MPO concentrations over time since the onset of symptoms ( $\mathrm{p}=0.737$ ), with a similar trend observed in both moderate and severe anaphylaxis $(\mathrm{p}=0.636)$ (Figure 2C).

\section{Soluble CD62L was consistently reduced during anaphylaxis}

A summary of the sCD62L concentrations at each timepoint by reaction severity is displayed in Figure 1D, with unadjusted comparisons between severities as indicated. In healthy controls $(\mathrm{n}=20)$, the median (IQR) sCD62L concentration was $708.8(157.8) \mathrm{ng} / \mathrm{mL}$. Upon enrolment, sCD62L was $29 \%(95 \%$ CI: 19, 38) lower in moderate patients than healthy control levels ( $\mathrm{p}<0.001)$, and $31 \%$ (95\% CI: 22, 40) lower in severe patients than controls ( $\mathrm{p}<0.001)$, and no difference was apparent between moderate and severe patients $(\mathrm{p}=0.829)$. sCD62L concentrations were also not significantly different at enrolment between patients based on whether they had already been administered adrenaline pre-hospital $(\mathrm{p}=0.279)$. Serum $\mathrm{sCD} 62 \mathrm{~L}$ levels remained stable over time $(\mathrm{p}=0.113)$, and there was no difference in trend $(\mathrm{p}=0.118)$ between moderate and severe reactions (Figure 2D).

MPO is elevated and $S C D 62 L$ is reduced in patients regardless of mast cell activation

There was no significant difference in plasma MPO concentrations in patients with and without a positive result for histamine and/or MCT $(\mathrm{p}=0.051)$ (Figure 3A). MPO concentrations were not associated with histamine concentrations $(\mathrm{p}=0.107)$ or MCT concentrations $(\mathrm{p}=0.101)$. There were no differences in $\mathrm{SCD} 62 \mathrm{~L}$ concentration in patients with and without mast cell activation $(\mathrm{p}=0.859)$ (Figure 3B). There were no associations between sCD62L and histamine $(\mathrm{p}=0.545)$ or MCT $(\mathrm{p}=0.144)$. There was also no association between MPO concentration and $\mathrm{sCD} 62 \mathrm{~L}$ concentration $(\mathrm{p} \geq 0.771)$.

This article is protected by copyright. All rights reserved. 


\section{Discussion}

This study assessed neutrophil activation in acute human anaphylaxis through the measurement of MPO and sCD62L concentrations in samples taken from patients over the course of their anaphylactic reaction. We identified evidence of mast cell activation, namely elevated histamine or MCT concentrations, in the majority of anaphylaxis patients. Concentrations of MPO in this cohort were significantly elevated in patients with anaphylaxis when compared to healthy controls, regardless of reaction severity. This result was apparent early in the reaction and was sustained during patient observation, treatment, and symptom resolution in the ED. MPO was also higher in severe patients than in moderate patients over the course of their reaction. Reduced sCD62L concentrations were evident in almost all anaphylaxis patients, regardless of reaction severity, when compared with healthy controls, and this was sustained over time since reaction onset. MPO concentrations were elevated and SCD62L concentrations were reduced similarly in patients with evidence of mast cell activation compared to those without. This study provides compelling evidence for the involvement of neutrophils during acute human anaphylaxis. Furthermore, this neutrophil activation occurs alongside mast cell activation, suggesting that neutrophils are actively involved during IgE-mediated anaphylaxis, perhaps in the amplification of the immune response.

This study is unique in that samples were obtained prospectively from patients during the acute course of anaphylaxis in the ED, enabling a real-time assessment of the immunological changes occurring over time. In this cohort, the majority of moderate reactions were triggered by foods whilst drugs were the primary trigger of severe reactions, a trend consistent with a previous sub-study of the CISS [38]. Other studies have identified a greater risk of death from reactions triggered by drugs than food- and insect-triggered anaphylaxis [39, 40]. The median interval between symptom onset and study enrolment, showed that the initial blood sampling occurred within the acute stage of the reaction and, most importantly, whilst the physiological symptoms of anaphylaxis were still present. It is unlikely that the results are attributable to something other than an anaphylactic presentation.

The precise role neutrophils might play in anaphylaxis is unclear, in particular whether neutrophil activation contributes to symptoms and reaction severity, or is simply a consequence of the reaction. However, as many neutrophil products, including MPO, elastase, and matrix metalloproteinase 9 (MMP9), cause non-specific tissue damage and symptoms akin to those observed during anaphylaxis (e.g. erythema, angioedema, and hypotension) [19, 26, 27, 41], it is likely that neutrophil activation contributes to the physiological changes in anaphylaxis, with higher concentrations of MPO (and other neutrophil products) leading to more severe symptoms. Indeed, animal and ex vivo studies suggested that neutrophils play a critical role in anaphylaxis, and that their activation is not a non-consequential by-product of the allergic response [13]. However, a direct clinical investigation during the acute phase of human anaphylaxis has not been reported. Additionally, neutrophils express receptors for both $\operatorname{IgE}$ and $\operatorname{IgG}[42,43]$ and can therefore directly respond to the allergen. It is possible that patients who experience more severe reactions have neutrophils that are more sensitised to the allergen, or simply in greater numbers, thereby driving a stronger inflammatory response. Alternatively, reactions that are more severe (particularly those with hypotension) are typically associated with a greater activation of mast cells.

Reduced serum concentration of sCD62L appears to be a ubiquitous and sustained response during anaphylaxis. Neutrophil activation is typically associated with CD62L shedding, which is required for the cells to traverse the endothelium. A previous study demonstrated evidence of CD62L shedding following the ex vivo culture of neutrophils from allergic patients after stimulation with their sensitizing antigen [44]. The serum concentrations of sCD62L in patients with widespread immune

This article is protected by copyright. All rights reserved. 
activation but not anaphylaxis do not follow a predictable trend; levels are elevated in some conditions and reduced in others [31-36]. Interestingly, sCD62L levels are also reduced in trauma, a condition arguably similar to anaphylaxis in that there is a rapid insult to the immune system from an external source, as opposed to a chronic condition or one that has developed more slowly. In our study, the reduction in sCD62L occurs even though the neutrophils are activated. It is possible that although the neutrophils are activated, they are not traversing the endothelium and therefore are not shedding any CD62L. Alternatively, circulating sCD62L could be non-specifically bound or masked by other proteins, bound to endothelial cells [33-36], or caught up in complexes generated by the acute anaphylactic response. In a condition such as anaphylaxis where the immune system is rapidly overstimulated, the peripheral blood is a complex cocktail of cytokines, chemokines, and other proteins. As such, it is possible that the true measureable concentration of sCD62L in the serum is suppressed.

This study provides the first evidence that neutrophils are activated during human anaphylaxis by showing elevation of MPO. Further studies are needed to investigate: the mechanism leading to neutrophil activation in the context of anaphylaxis; whether neutrophils contribute to the initiation and/or amplification of the immune response; and the potential effect of neutrophil activation on clinical manifestations.

\section{Limitations}

The CISS criteria only captured patients who were significantly unwell and as a result, patients with mild allergic reactions were not recruited. Furthermore, patient sampling was dependent on the availability of the enrolling nurse/physician and their experience with the study protocol. While early sampling times post-enrolment were adhered to, discharge samples were more difficult to obtain, affecting the number of patient samples available at this sampling time. However, we utilized MLE in our longitudinal analysis which is known to overcome the issue of selection bias when data are missing at random. Future studies will be strengthened by the inclusion of patients encompassing the full spectrum of allergic disease and in convalescence.

\section{Acknowledgements}

The authors appreciate and acknowledge the research nursing staff at Royal Perth, Fremantle, Armadale, Bunbury, and Austin hospitals, including Ellen MacDonald (Clinical Nurse Manager), for identifying patients for the study and collecting and processing blood samples. The authors also appreciate Mrs Claire Neil for her expert assistance in optimising the laboratory methods. The authors acknowledge the facilities, scientific and technical assistance of the Australian Microscopy \& Microanalysis Research Facility at the Centre for Microscopy, Characterisation \& Analysis, University of Western Australia, a facility funded by the University, State and Commonwealth Governments. Prof. Simon Brown is supported by a NHMRC Career Development Fellowship, and laboratory work was supported by the RPH Medical Research Fund. Funding bodies played no role in study design, data collection, or analysis.

This article is protected by copyright. All rights reserved. 


\section{Author contributions}

All authors reviewed and approved the final manuscript. AF contributed to the study concept and design, performed the laboratory experiments, contributed to data analysis, and drafted the manuscript. EB contributed to the data analysis and manuscript preparation. SFS contributed to the study concept and design, and obtaining funding support. DMF, GA, YN, SPJM, HM, and MR contributed to the collection of data. SB contributed extensive statistical knowledge to assist in data analysis and interpretation. SGAB contributed to the study concept and design, obtaining funding support, and collection of data.

\section{Conflicts of interest}

The authors declare that they have no conflicts of interest.

\section{References}

1. Poulos LM, Waters AM, Correll PK, Loblay RH, Marks GB, Trends in hospitalizations for anaphylaxis, angioedema, and urticaria in Australia, 1993-1994 to 2004-2005. J Allergy Clin Immunol 2007;120: 878-84.

2. Rudders SA, Arias SA, Camargo CA, Trends in hospitalizations for food-induced anaphylaxis in US children, 2000-2009. J Allergy Clin Immunol 2014;134: 960.

3. Sampson HA, Muñoz-Furlong A, Campbell RL, Adkinson Jr NF, Bock SA, Branum A, Brown SGA, Camargo Jr CA, Cydulka R, Galli SJ, Gidudu J, Gruchalla RS, Harlor Jr AD, Hepner DL, Lewis LM, Lieberman PL, Metcalfe DD, O'Connor R, Muraro A, Rudman A, Schmitt C, Scherrer D, Simons FER, Thomas S, Wood JP, Decker WW, Second symposium on the definition and management of anaphylaxis: Summary report-Second National Institute of Allergy and Infectious Disease/Food Allergy and Anaphylaxis Network symposium. J Allergy Clin Immunol 2006;117: 391-97.

4. Brown SGA, Clinical features and severity grading of anaphylaxis. J Allergy Clin Immunol 2004;114: 371-76.

5. Brown SGA, Blackman KE, Heddle RJ, Can serum mast cell tryptase help diagnose anaphylaxis? Emerg Med Australas 2004;16: 120-24.

6. Stone SF, Cotterell C, Isbister GK, Holdgate A, Brown SG, Elevated serum cytokines during human anaphylaxis: Identification of potential mediators of acute allergic reactions. J Allergy Clin Immunol 2009;124: 786-92.

7. Lin RY, Schwartz LB, Curry A, Pesola GR, Knight RJ, Lee HS, Bakalchuk L, Tenenbaum C, Westfal RE, Histamine and tryptase levels in patients with acute allergic reactions: An emergency department-based study. J Allergy Clin Immunol 2000;106: 65-71.

8. Hermann K, von Tschirschnitz M, Ebner von Eschenbach C, Ring J, Histamine, tryptase, norepinephrine, angiotensinogen, angiotensin-converting enzyme, angiotensin I and II in

This article is protected by copyright. All rights reserved. 
plasma of patients with hymenoptera venom anaphylaxis. Int Arch Allergy Immunol 1994;104: 379-84.

9. Ogawa Y, Grant JA, Mediators of Anaphylaxis. Immunol Allergy Clin North Am 2007;27: 249-60.

10. Kemp SF, Lockey RF, Anaphylaxis: a review of causes and mechanisms. J Allergy Clin Immunol 2002;110: 341-48.

11. Ben-Shoshan M, Clarke A, Anaphylaxis: past, present and future. Allergy 2010;66: 1-14.

12. Schwartz LB, Yunginger JW, Miller J, Bokhari R, Dull D, Time course of appearance and disappearance of human mast cell tryptase in the circulation after anaphylaxis. J Clin Invest 1989;83: 1551-5.

13. Jönsson F, Mancardi DA, Kita Y, Karasuyama H, Iannascoli B, Van Rooijen N, Shimizu T, Daëron M, Bruhns P, Mouse and human neutrophils induce anaphylaxis. J Clin Invest 2011;121: 1484-96.

14. Stone SF, Bosco A, Jones A, Cotterell CL, van Eeden PE, Arendts G, Fatovich DM, Brown SGA, Genomic Responses during Acute Human Anaphylaxis are Characterized by Upregulation of Innate Inflammatory Gene Networks. PLoS One 2014;9: e101409.

15. Baici A, Salgam P, Cohen G, Fehr K, Böni A, Action of collagenase and elastase from human polymorphonuclear leukocytes on human articular cartilage. Rheumatol Int 1982;2: 11-16.

16. Van den Steen PE, Proost P, Grillet B, Brand DD, Kang AH, Van Damme J, Opdenakker G, Cleavage of denatured natural collagen type II by neutrophil gelatinase $\mathrm{B}$ reveals enzyme specificity, post-translational modifications in the substrate, and the formation of remnant epitopes in rheumatoid arthritis. FASEB J 2002;16: 379-89.

17. Wong SH, Francis N, Chahal H, Raza K, Salmon M, Scheel-Toellner D, Lord JM, Lactoferrin is a survival factor for neutrophils in rheumatoid synovial fluid. Rheumatology 2009;48: 3944.

18. Oseas R, Yang H, Baehner R, Boxer L, Lactoferrin: a promoter of polymorphonuclear leukocyte adhesiveness. Blood 1981;57: 939-45.

19. Wright HL, Moots RJ, Bucknall RC, Edwards SW, Neutrophil function in inflammation and inflammatory diseases. Rheumatology 2010;49: 1618-31.

20. Prokopowicz Z, Marcinkiewicz J, Katz DR, Chain BM, Neutrophil myeloperoxidase: soldier and statesman. Arch Immunol Ther Exp (Warsz) 2012;60: 43-54.

21. Chen A, Engel P, Tedder TF, Structural requirements regulate endoproteolytic release of the L-selectin (CD62L) adhesion receptor from the cell surface of leukocytes. J Exp Med 1995;182: 519-30.

22. Gross V, Andreesen R, Leser HG, Ceska M, Liehl E, Lausen M, Farthmann EH, SchÖLmerich J, lnterleukin-8 and neutrophil activation in acute pancreatitis. Eur J Clin Invest 1992;22: 200-03.

This article is protected by copyright. All rights reserved. 
23. Mann B, Chung K, Blood neutrophil activation markers in severe asthma: lack of inhibition by prednisolone therapy. Respir Res 2006;7: 59.

24. Foell D, Wittkowski H, Hammerschmidt I, Wulffraat N, Schmeling H, Frosch M, Horneff G, Kuis W, Sorg C, Roth J, Monitoring neutrophil activation in juvenile rheumatoid arthritis by S100A12 serum concentrations. Arthritis Rheum 2004;50: 1286-95.

25. Ekberg-Jansson A, Andersson B, Bake B, Boijsen M, Enanden I, Rosengren A, Skoogh BE, TylÉN U, Venge P, LÖFdahl CG, Neutrophil-associated activation markers in healthy smokers relates to a fall in DLCO and to emphysematous changes on high resolution CT. Respir Med 2001;95: 363-73.

26. Arnhold J, Properties, functions, and secretion of human myeloperoxidase. Biochemistry (Mosc) 2004;69: 4-9.

27. Kothari N, Keshari RS, Bogra J, Kohli M, Abbas H, Malik A, Dikshit M, Barthwal MK, Increased myeloperoxidase enzyme activity in plasma is an indicator of inflammation and onset of sepsis. J Crit Care 2011;26: 435. e1-35. e7.

28. Lewinsohn DM, Bargatze RF, Butcher EC, Leukocyte-endothelial cell recognition: evidence of a common molecular mechanism shared by neutrophils, lymphocytes, and other leukocytes. J Immunol 1987;138: 4313-21.

29. Schleiffenbaum B, Spertini O, Tedder TF, Soluble L-selectin is present in human plasma at high levels and retains functional activity. J Cell Biol 1992;119: 229-38.

30. Rambeaud M, Pighetti G, Impaired neutrophil migration associated with specific bovine CXCR2 genotypes. Infect Immun 2005;73: 4955-59.

31. Font J, Pizcueta P, Ramos-Casals M, Cervera R, García-Carrasco M, Navarro M, Ingelmo M, Engel P, Increased serum levels of soluble l-selectin (CD62L) in patients with active systemic lupus erythematosus (SLE). Clin Exp Immunol 2000;119: 169-74.

32. Kordonouri O, Bührer C, Circulating L-selectin concentrations in children with recent-onset IDDM. J Pediatr Endocrinol Metab 2000;13: 85-90.

33. Stengel D, Orth M, Tauber R, Sehouli J, Hentsch S, Thielemann HK, Laun R, Ekkernkamp A, Shed L-Selectin (sCD62L) Load in Trauma Patients. J Surg Res 2001;99: 321-27.

34. Donnelly SC, Haslett C, Robertson CE, Carter DC, Ross JA, Grant IS, Tedder TF, Role of selectins in development of adult respiratory distress syndrome. The Lancet 1994;344: 21519.

35. Stengel D, Bauwens K, Keh D, Gerlach H, Ekkernkamp A, Tauber R, Kerner T, Prognostic value of an early soluble L-selectin (sCD62L) assay for risk assessment in blunt multiple trauma: a metaanalysis. Clin Chem 2005;51: 16-24.

36. Herold R, Stibenz D, Hartmann R, Henze G, Bührer C, Soluble 1-selectin (sCD62L) in relapsed childhood acute lymphoblastic leukaemia. Br J Haematol 2002;119: 677-84.

This article is protected by copyright. All rights reserved. 
37. Arendts G, Stone SF, Fatovich DM, van Eeden P, MacDonald E, Brown SG, Critical illness in the emergency department: lessons learnt from the first 12 months of enrolments in the Critical Illness and Shock Study. Emerg Med Australas 2012;24: 31-36.

38. Brown SG, Stone SF, Fatovich DM, Burrows SA, Holdgate A, Celenza A, Coulson A, Hartnett L, Nagree Y, Cotterell C, Anaphylaxis: clinical patterns, mediator release, and severity. J Allergy Clin Immunol 2013;132: 1141-49. e5.

39. Pumphrey RS, Fatal anaphylaxis in the UK, 1992-2001Novartis Found Symp. Chichester, New York: John Wiley, 2004:116.

40. Low I, Stables S, Anaphylactic deaths in Auckland, New Zealand: a review of coronial autopsies from 1985 to 2005. Pathology 2006;38: 328-32.

41. Deby-Dupont G, Deby C, Lamy M, Neutrophil myeloperoxidase revisited: it's role in health and disease. Intensivmedizin und Notfallmedizin 1999;36: 500-13.

42. Gounni AS, Lamkhioued B, Koussih L, Ra C, Renzi PM, Hamid Q, Human neutrophils express the high-affinity receptor for immunoglobulin E (Fc epsilon RI): role in asthma. FASEB J 2001;15: 940-9.

43. Repp R, Valerius T, Sendler A, Gramatzki M, Iro H, Kalden JR, Platzer E, Neutrophils express the high affinity receptor for IgG (Fc gamma RI, CD64) after in vivo application of recombinant human granulocyte colony-stimulating factor. Blood 1991;78: 885-9.

44. Monteseirin J, Chacon P, Vega A, Sánchez- Monteseirín H, Asturias J, Martinez A, Guardia P, Pérez- Cano R, Conde J, 1- Selectin expression on neutrophils from allergic patients. Clin Exp Allergy 2005;35: 1204-13.

\section{Legends to Figures}

Figure 1: Protein concentrations during anaphylaxis. A) Histamine was measured in moderate (T0 $n=23, T 1 n=22, T 3 n=17$, and discharge $n=4)$ and severe $(T 0 n=32, T 1 n=31, T 3 n=25$, and discharge $\mathrm{n}=7$ ) patients. The dashed line indicates $1.2 \mathrm{ng} / \mathrm{mL}$, the $99^{\text {th }}$ percentile of healthy controls. B) Mast cell tryptase was measured in moderate (T0 $n=31, T 1 n=29, T 3 n=25$, and discharge $n=7$ ) and severe (T0 $n=36, T 1 n=35, T 3 n=33$, and discharge $n=12$ ) patients. The dashed line indicates $11.4 \mathrm{ng} / \mathrm{mL}$, the $95^{\text {th }}$ percentile of healthy controls. C) Myeloperoxidase was measured in moderate (T0 n=27, T1 $n=26, T 3 n=20$, and discharge $n=3)$ and severe $(T 0 n=36, T 1 n=35, T 3 n=29$, and discharge $n=9)$ patients. The dashed line indicates $16.24 \mathrm{ng} / \mathrm{mL}$, the median concentration of healthy controls $(\mathrm{n}=23)$. D) Soluble CD62L concentrations was measured in moderate (T0 n=31, T1 n=30, T3 n=28, and discharge $n=7)$ and severe (T0 $n=33, T 1 n=33, T 3 n=32$, and discharge $n=12)$ patients. The dashed line indicates $708.8 \mathrm{ng} / \mathrm{mL}$, the median concentration of healthy controls $(\mathrm{n}=20)$.

Note: Raw values are plotted and p-values are derived using random effects linear or Tobit regression models testing the ratio of the two means following log transformation.

This article is protected by copyright. All rights reserved. 
Figure 2: Changes in histamine, mast cell tryptase (MCT), myeloperoxidase (MPO), and soluble CD62L (sCD62L) concentrations over the course of anaphylactic reactions. Margins plots show the predicted concentrations (back transformed from log variables) over the first 5 hours since the onset of symptoms in moderate (dotted) and severe (solid) patients based on the appropriate random effects linear or Tobit regression models (adjusted for age, sex, and trigger). A) The dashed line indicates 1.2 $\mathrm{ng} / \mathrm{mL}$, the $99^{\text {th }}$ percentile of healthy controls. B) The dashed line indicates $11.4 \mathrm{ng} / \mathrm{mL}$, the $95^{\text {th }}$ percentile of healthy controls. C) The dashed line indicates $16.24 \mathrm{ng} / \mathrm{mL}$, the median concentration of healthy controls $(\mathrm{n}=23)$. D) The dashed line indicates $708.8 \mathrm{ng} / \mathrm{mL}$, the median concentration of healthy controls $(n=20)$.

Figure 3: Concentrations of myeloperoxidase and soluble CD62L in anaphylaxis patients with/without evidence of mast cell activation (as determined by histamine and mast cell tryptase (MCT) concentrations). A) The dashed line indicates $16.24 \mathrm{ng} / \mathrm{mL}$, the median concentration of healthy controls $(\mathrm{n}=23)$. B) The dashed line indicates $708.8 \mathrm{ng} / \mathrm{mL}$, the median concentration of healthy controls $(n=20)$.

Note: p-values are derived using random effects linear regression models testing the ratio of the two means following log transformation.

Table 1: Patient demographics and clinical observations

\begin{tabular}{|c|c|c|c|c|}
\hline & $\begin{array}{l}\text { Moderate } \\
\text { anaphylaxis }\end{array}$ & $\begin{array}{l}\text { Severe } \\
\text { anaphylaxis }\end{array}$ & $P$ value & All \\
\hline $\mathbf{n}$ & 35 & 37 & & 72 \\
\hline Age (years), mean (SD) & $33(13)$ & $43(15)$ & 0.007 & $38(15)$ \\
\hline Male gender, n (\%) & $18(51.4)$ & $16(43.2)$ & 0.487 & $34(47.2)$ \\
\hline \multicolumn{5}{|l|}{ Cause } \\
\hline Drug, $n(\%)$ & $6(17.1)$ & $20(54.1)$ & & $26(36.1)$ \\
\hline Food, n (\%) & $19(54.3)$ & $6(16.2)$ & & $25(34.7)$ \\
\hline Insect, n (\%) & $5(14.3)$ & $3(8.1)$ & -0.003 & $8(11.1)$ \\
\hline $\begin{array}{l}\text { Physical (including food + exercise), } n \\
(\%)\end{array}$ & $2(5.7)$ & $2(5.4)$ & & $4(5.6)$ \\
\hline Other/Unknown, n (\%) & $3(8.6)$ & $6(16.2)$ & & $9(12.5)$ \\
\hline Onset to enrolment (mins), mean (SD) & $71(34)$ & $77(36)$ & 0.480 & $74(35)$ \\
\hline
\end{tabular}

This article is protected by copyright. All rights reserved. 


\begin{tabular}{|c|c|c|c|c|}
\hline \multicolumn{5}{|l|}{ Symptoms } \\
\hline Any skin feature, $n(\%)$ & $34(97.1)$ & $37(100)$ & 0.300 & $71(98.6)$ \\
\hline Any GI feature, n (\%) & $13(37.1)$ & $18(48.7)$ & 0.324 & $31(43.1)$ \\
\hline Any respiratory feature, $n(\%)$ & $34(97.1)$ & $29(78.4)$ & 0.016 & $63(87.5)$ \\
\hline Hypoxemia, n (\%) & - & $5(13.5)$ & - & $5(6.9)$ \\
\hline Cyanosis, n (\%) & - & $9(24.3)$ & - & $9(12.5)$ \\
\hline Any cardiovascular feature, n (\%) & $8(22.9)$ & $36(97.3)$ & $<0.001$ & $44(61.1)$ \\
\hline Hypotension, n (\%) & - & $26(70.3)$ & - & $26(36.1)$ \\
\hline LOC/Collapse, n (\%) & - & $13(35.1)$ & - & $13(18.1)$ \\
\hline \multicolumn{5}{|l|}{ Treatments } \\
\hline 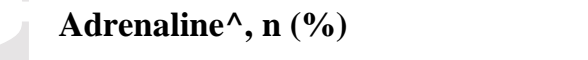 & $31(88.6)$ & $36(97.3)$ & 0.145 & $67(93.1)$ \\
\hline Pre-hospital, n (\%) & $8(22.9)$ & $20(54.1)$ & 0.007 & $28(38.9)$ \\
\hline Steroids, $\mathbf{n}(\%)$ & $20(57.1)$ & $28(75.7)$ & 0.095 & $48(66.7)$ \\
\hline Fluids, n (\%) & $16(45.7)$ & $28(75.7)$ & 0.009 & $44(61.1)$ \\
\hline $\begin{array}{l}\text { Positive histamine* (>1.2ng/mL), n } \\
(\%)\end{array}$ & $12(52.2)$ & $21(65.6)$ & 0.315 & $33(60.0)$ \\
\hline $\begin{array}{l}\text { Positive MCT** (>11.4 ng/mL, or } \\
\Delta \text { MCT > 2ng/mL), n }(\%)\end{array}$ & $15(48.4)$ & $32(88.9)$ & $<0.001$ & $47(70.2)$ \\
\hline
\end{tabular}

$\mathrm{GI}=$ gastrointestinal, $\mathrm{LOC}=$ loss of consciousness, $\mathrm{MCT}=$ mast cell tryptase, $\triangle \mathrm{MCT}=$ difference between highest and lowest observed MCT concentrations

Skin features = erythema, urticaria, periorbital oedema, angioedema

GI features = nausea, vomiting, abdominal/pelvic pain, incontinence

Respiratory features = dyspnea, stridor, wheeze, chest/throat tightness, hypoxemia, cyanosis

Cardiovascular features $=$ dizziness, diaphoresis, confusion, hypotension, LOC, collapse

$\wedge=$ adrenaline administered at any stage

Note, due to sample availability:

* Histamine was measured in 23 moderate and 32 severe patients at enrolment

** MCT was measured in 31 moderate and 36 severe patients at enrolment

This article is protected by copyright. All rights reserved. 

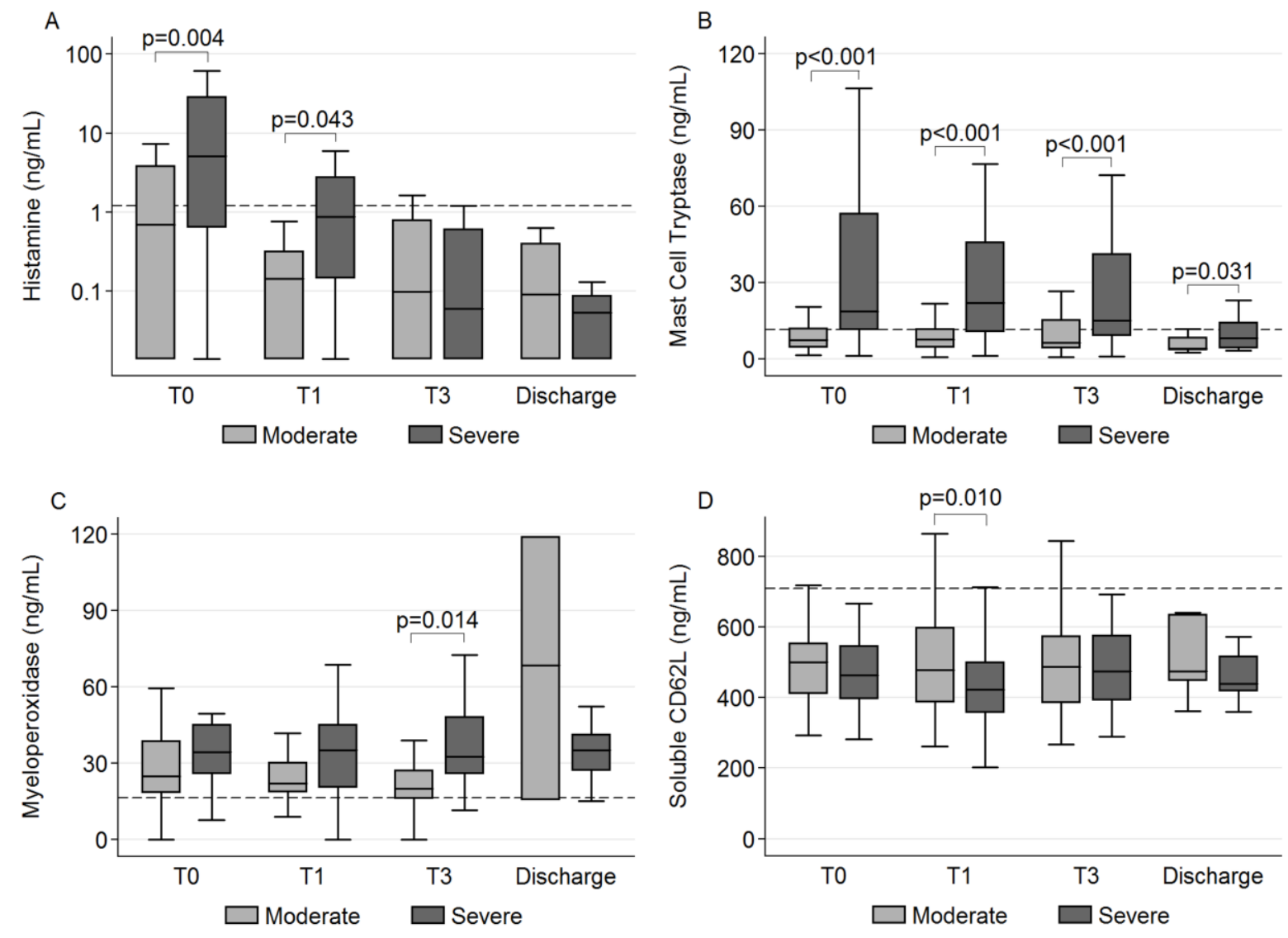

excludes outlier values

This article is protected by copyright. All rights reserved. 

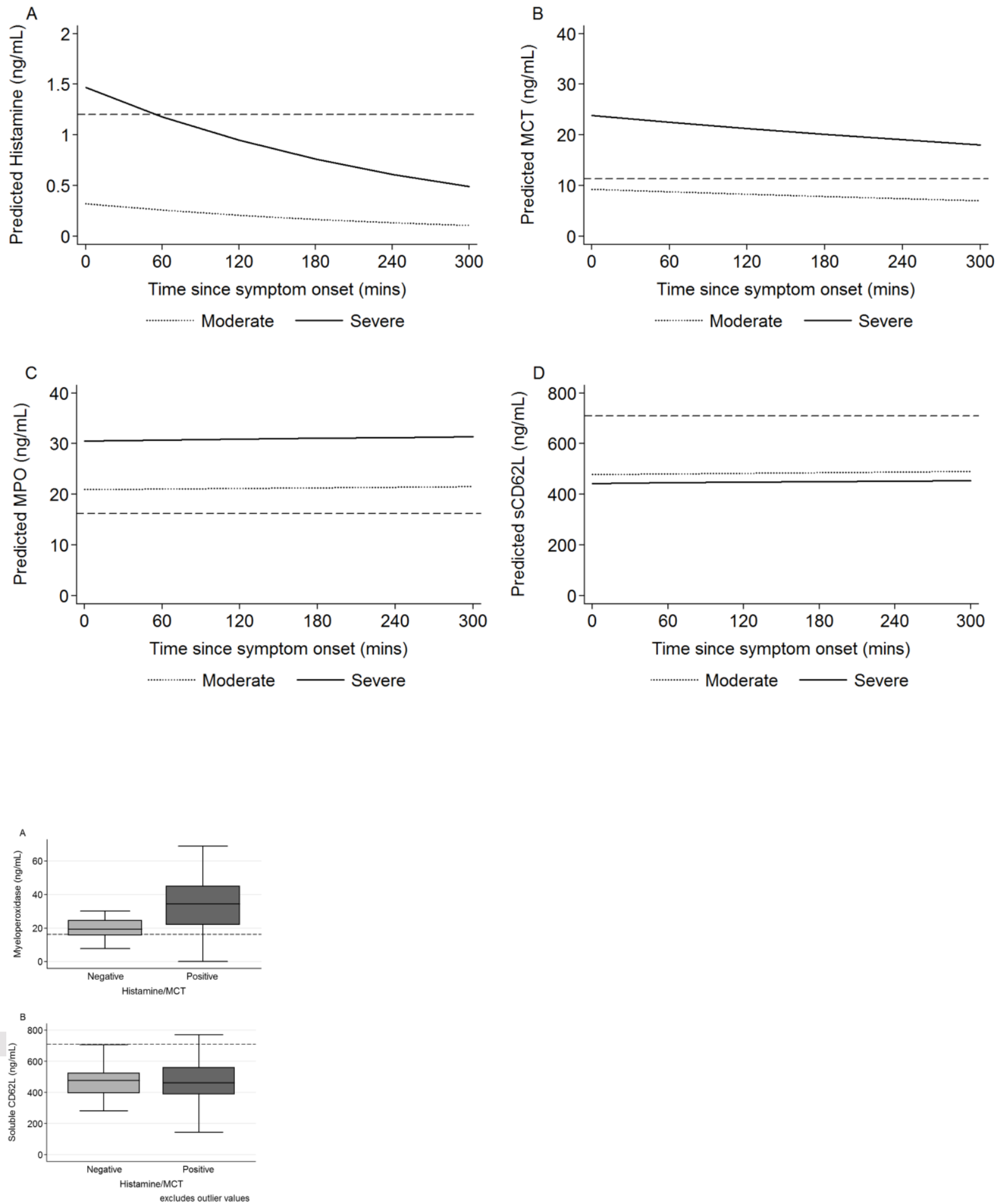

This article is protected by copyright. All rights reserved. 